\title{
Aldosterone: a mediator of retinal ganglion cell death and the potential role in the pathogenesis in normal-tension glaucoma
}

\author{
E Nitta ${ }^{\star, 1}$, K Hirooka $^{1}$, K Tenkumo ${ }^{1}$, T Fujita ${ }^{1}$, A Nishiyama ${ }^{2}$, T Nakamura ${ }^{3}$, T Itano ${ }^{3}$ and F Shiraga ${ }^{1,4}$
}

Glaucoma is conventionally defined as a chronic optic neuropathy characterized by progressive loss of retinal ganglion cells (RGCs) and optic nerve fibers. Although glaucoma is often associated with elevated intraocular pressure (IOP), significant IOP reduction does not prevent progression of the disease in some glaucoma patients. Thus, exploring IOP-independent mechanisms of RGC loss is important. We describe chronic systemic administration of aldosterone and evaluate its effect on RGCs in rat. Aldosterone was administered via an osmotic minipump that was implanted subcutaneously into the mid-scapular region. Although systemic administration of aldosterone caused RGC loss associated with thinning of the retinal nerve fiber layer without elevated IOP, the other cell layers appeared to be unaffected. After chronic administration of aldosterone, RGC loss was observed at 2 weeks in the peripheral retina and at 4 weeks in the central retina. However, administration of mineralocorticoid receptor blocker prevented RGC loss. These results demonstrate aldosterone is a critical mediator of RGC loss that is independent of IOP. We believe this rat normal-tension glaucoma (NTG) animal model not only offers a powerful system for investigating the mechanism of neurodegeneration in NTG, but can also be used to develop therapies directed at IOP-independent mechanisms of RGC loss.

Cell Death and Disease (2013) 4, e711; doi:10.1038/cddis.2013.240; published online 4 July 2013

Subject Category: Neuroscience

Although therapeutic methods aimed at alleviating the basic pathologic process of normal-tension glaucoma (NTG) have yet to be established, there seems to be little doubt that intraocular pressure (IOP) is a risk factor in most patients. ${ }^{1-4}$ However, a reduction in IOP does not prevent progression in patients with NTG, ${ }^{5}$ which indicates that factors other than an elevated IOP are involved in the progression of glaucoma. ${ }^{6}$ The association of glaucoma with various systemic vascular diseases including low systemic blood pressure, transient nocturnal decreases in blood pressure, hypertension, migraine, vasospasm, and diabetes has been reported. ${ }^{6-9}$ Many patients with chronic open-angle glaucoma have coexisting vascular disorders, with the most common finding reported to be systemic hypertension, which occurs in $48 \%$ of the total chronic open-angle glaucoma population. ${ }^{10}$ All of these observations suggest the possibility that factors not dependent on the IOP may contribute to the disease progress. Therefore, elucidation of such factors is necessary if we are to understand the pathogenesis of glaucoma and in order to be able to further guide efforts toward improved therapeutics.
The renin-angiotensin-aldosterone system (RAAS) is a major controller of systemic blood pressure. Abnormal activation of this system has been postulated to participate in the occurrence of end-organ damage in hypertensive patients. ${ }^{11,12}$ Aldosterone is a steroid hormone that elicits its effects by binding to the mineralocorticoid receptor (MR). Although many studies have investigated the role of angiotensin II (Ang II) in mediating cardiovascular damage, relatively little attention has been paid to the role of aldosterone, which is the end product of the RAAS. However, there are data that suggest aldosterone may have an important role in the pathogenesis of cardiovascular diseases, a role that is independent of Ang II. As compared with patients with essential hypertension, patients with primary aldosteronism, in which Ang II levels are usually very low, have a higher incidence of left ventricular hypertrophy, ${ }^{13}$ albuminuria, ${ }^{14}$ and stroke. ${ }^{15,16}$ Furthermore, experimental animal data support a role for aldosterone in mediating cardiovascular injury in the kidney and brain. ${ }^{17,18}$

We recently reported that the expression of angiotensin II type 1 receptor (AT1-R) in the retina is increased after ischemia-reperfusion ${ }^{19,20}$ and that treatment with an

\footnotetext{
${ }^{1}$ Department of Ophthalmology, Kagawa University Faculty of Medicine, 1750-1 Ikenobe, Miki, Kagawa, Japan; ${ }^{2}$ Department of Pharmacology, Kagawa University Faculty of Medicine, 1750-1 lkenobe, Miki, Kagawa, Japan; ${ }^{3}$ Department of Neurobiology, Kagawa University Faculty of Medicine, 1750-1 lkenobe, Miki, Kagawa, Japan and ${ }^{4}$ Department of Ophthalmology, Okayama University Graduate School of Medicine, Density and Pharmaceutical Sciences, 2-5-1 Shikata-cho, Okayama, Japan *Corresponding author: E Nitta, Department of Ophthalmology, Kagawa University Faculty of Medicine, 1750-1 Ikenobe, Miki, Kagawa 761-0793 Japan. Tel: + 8187891 2211; Fax: + 8187891 2212; E-mail: anchovy_e@yahoo.co.jp

Keywords: aldosterone; retinal ganglion cell; normal-tension glaucoma; intraocular pressure

Abbreviations: NTG, normal-tension glaucoma; IOP, intraocular pressure; RAAS, renin-angiotensin-aldosterone system; MR, mineralocorticoid receptor; Ang, angiotensin; AT1-R, angiotensin II type 1 receptor; ACE, angiotensin-converting enzyme; ARB, angiotensin II type 1 receptor blocker; RGC, retinal ganglion cell; IPL, inner plexiform layer; INL, inner nuclear layer; OPL, outer plexiform layer; ONL, outer nuclear layer; ROS, reactive oxygen species; MCP-1, macrophage chemoattractant protein 1; DMSO, dissolved in dimethyl sulfoxide; CMC, carboxymethyl cellulose; $\mathrm{HE}$, hematoxylin and eosin

Received 15.5.13; revised 31.5.13; accepted 03.6.13; Edited by A Verkhratsky
} 
angiotensin-converting enzyme (ACE) inhibitor, AT1-R blocker (ARB), and MR antagonist reduced retinal ischemia-reperfusion injury. ${ }^{19,21}$ Moreover, we have also shown that intravitreal injection of aldosterone reduced the number of retinal ganglion cells (RGCs). ${ }^{20}$ To investigate the role of aldosterone in mediating retinal injury, we infused aldosterone in rats using an experimental model in which an osmotic minipump was subcutaneously implanted at the dorsum of the neck.

\section{Results}

Loss of RGCs in aldosterone-treated rats. Figure 1a shows representative results for the RGC labeling in the $8 \mu \mathrm{g} / \mathrm{kg} / \mathrm{day}, 80 \mu \mathrm{g} / \mathrm{kg} /$ day aldosterone- and vehicle-treated rats for 6 weeks. The number of RGCs were similar between the vehicle- and $8 \mu \mathrm{g} / \mathrm{kg} /$ day aldosterone-treated rats in the central $(99.6 \pm 2.0 \%, P=0.99)$ and peripheral retina (94.3 $\pm 6.2 \%, P=0.56)$. However, RGCs were decreased in the $80 \mu \mathrm{g} / \mathrm{kg} /$ day aldosterone-treated rats in the central $(64.2 \pm 3.9 \%, P<0.001)$ and peripheral retina $(66.7 \pm 3.9 \%$, $P=0.001, n=4)$.

To determine the time point where the RGCs decreased in aldosterone-treated rats, the numbers of RGCs were counted every week. At 2 weeks after the continual administration of aldosterone, RGCs were significantly decreased in the peripheral retina $(P=0.03)$, whereas the cell density for the central RGCs showed no significant decrease $(P>0.99)$ (Figure 2). At 4 weeks after continual administration of aldosterone, RGCs were decreased not only in the peripheral but also in the central retina ( $P<0.001, n=4$ for each week). These data suggested that in aldosterone-treated rats, the tendency for neuronal degeneration in the ganglion cell layer initially started from the peripheral retina and then spread to the central retina.
To determine if there was degeneration of any of the other retinal neurons, we performed a retinal layer thickness analysis. Thickness measurements in animals treated with
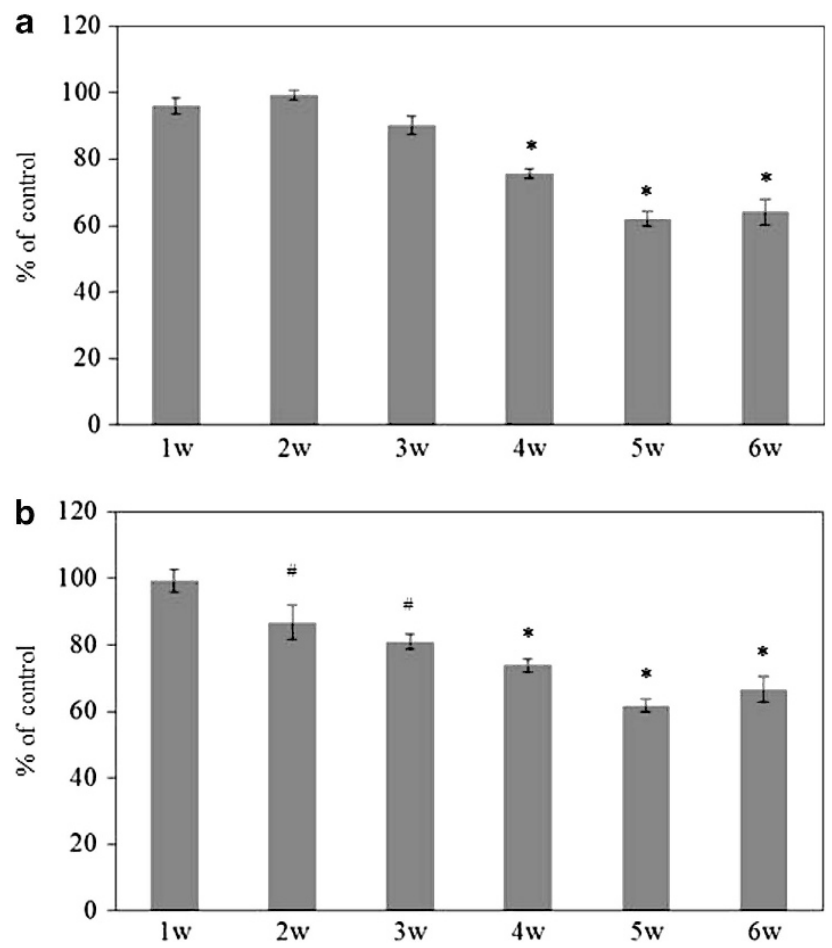

Figure 2 The number of RGCs in the eyes treated weekly with $80 \mu \mathrm{g} / \mathrm{kg} / \mathrm{day}$ aldosterone. (a) In the central retina, RGC was decreased 4 weeks after the administration of aldosterone. (b) In the peripheral retina, however, reduction in the number of RGCs was already detected at 2 weeks after the administration of aldosterone. Results are expressed as the mean \pm S.E.M. ( $n=4$ in each week). ${ }^{\#} P<0.05$, ${ }^{*} P<0.001$ versus control (Dunnett's multiple comparison test)
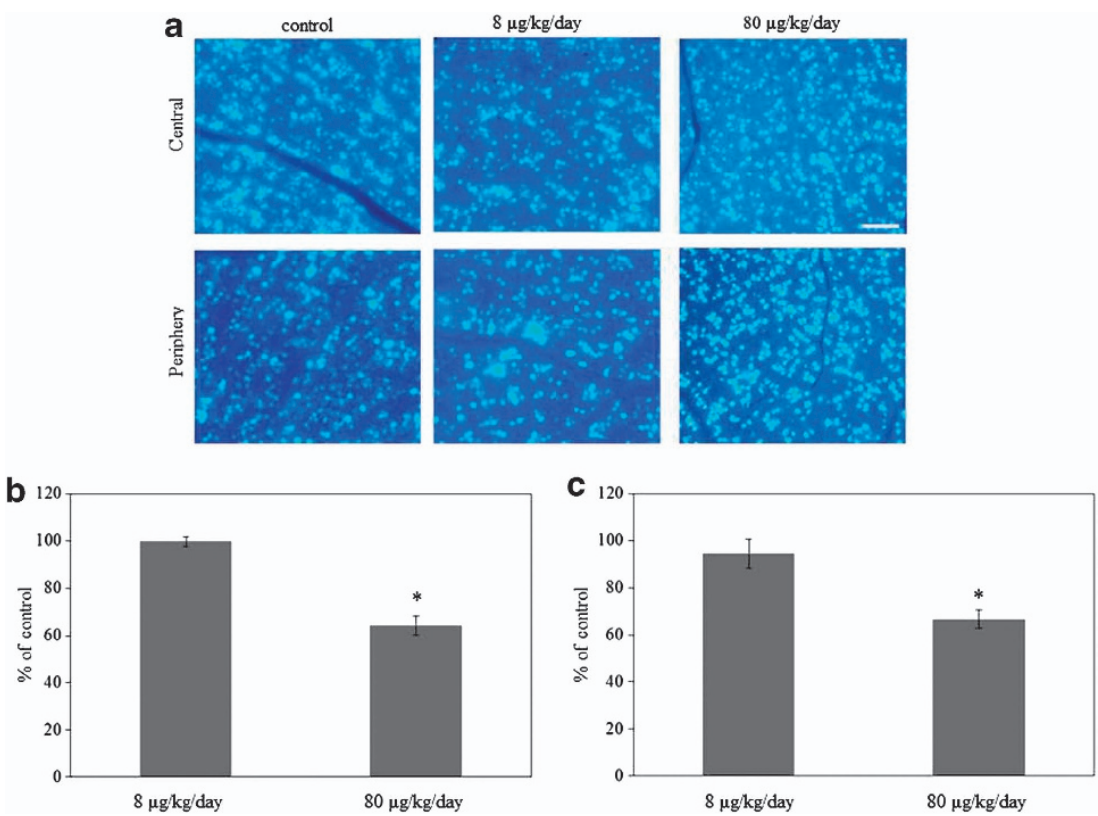

Figure 1 Effect of aldosterone on retinal ganglion cell (RGC) death. (a) Retrograde labeling of RGCs treated with $8 \mu \mathrm{g} / \mathrm{kg} /$ day or $80 \mu \mathrm{g} / \mathrm{kg} / \mathrm{day}$ aldosterone for 6 weeks, and a normal control eye. Micrographs of the central and peripheral areas were taken $\sim 1$ and $4 \mathrm{~mm}$ away from the optic nerve head. Scale bar, $100 \mu \mathrm{m}$. RGCs were counted in the central (b) and peripheral (c) areas. Results are expressed as the mean \pm SEM ( $n=4$ in each group). ${ }^{*} P<0.001$ versus control (Dunnett's multiple comparison test) 
$8 \mu \mathrm{g} / \mathrm{kg} /$ day aldosterone for 6 weeks were $92.0 \pm 5.0 \%$ $(P=0.64)$ for the inner plexiform layer (IPL), $101.6 \pm 2.3 \%$ $(P=0.87)$ for the inner nuclear layer (INL), $80.2 \pm 7.3 \%$ $(P=0.46)$ for the outer plexiform layer (OPL), and $99.4 \pm 3.2 \%(P=0.98)$ for the outer nuclear layer (ONL) (Figure 3). In animals treated with $80 \mu \mathrm{g} / \mathrm{kg} /$ day aldosterone for 6 weeks, the thicknesses were $89.5 \pm 1.7 \%(P=0.47)$ for IPL, 101.3 $\pm 2.9 \%(P=0.90)$ for INL, $89.6 \pm 6.2 \%(P=0.79)$ for OPL, and $96.3 \pm 1.0 \%(P=0.64)$ for ONL $(n=4$ in each group). These findings suggested that aldosterone-treated rats showed a severe neuronal loss only in the ganglion cell layer.

Degeneration of optic nerve in aldosterone-treated rats. Degeneration of the optic nerve is one of the hallmarks of glaucoma. In association with the progressive loss of RGCs, rats treated with aldosterone for 6 weeks showed attenuation of the retinal nerve fiber layer (Figure $4 b$ ) compared with controls (Figure 4a). Quantitative analysis showed there was significant nerve fiber layer thinning in the aldosterone-treated rats $(13.2 \pm 0.9 \mu \mathrm{m}, P=0.004)$ at the central retina ( $200 \mu \mathrm{m}$ from the optic nerve head) when compared with normal rats (Figure 4c) $(8.4 \pm 0.6 \mu \mathrm{m}, n=4$ in each group). Consistent with severe RGC loss, optic nerve cupping was also apparent in the aldosterone-treated rats.
Normal IOP in aldosterone-treated rats. To determine whether the IOP was affected in aldosterone-treated rats, IOP was measured every week. No significant differences in the IOP levels were detected between the vehicle- and aldosterone-treated rats (Figure 5) $(P=0.09 \sim 0.99, n=4$ in each week). These results suggested that RGC loss in aldosterone-treated rats was IOP-independent.

Effect of spironolactone on RGC survival. To assess aldosterone involvement in RGC loss, we next examined the effect of the MR antagonist spironolactone on RGC loss in the aldosterone-treated rat. Figure 6 a shows representative results of the RGC labeling in rats treated with aldosterone alone and those treated with the combination of spironolactone with aldosterone for 6 weeks. As shown in Figures $6 \mathrm{~b}$ and $\mathrm{c}$, administration of spironolactone significantly prevented RGC loss in the central $(81.1 \pm 4.4 \%, P=0.02)$ and the peripheral retina $(90.0 \pm 2.9 \%, P=0.001)(n=4$ in each group). The protective effect of the MR antagonist suggests that aldosterone is partly involved in RGC loss.

\section{Discussion}

Systemic administration of aldosterone resulted in progressive RGC loss and glaucomatous optic nerve degeneration without elevated IOP. The results of this study raise the
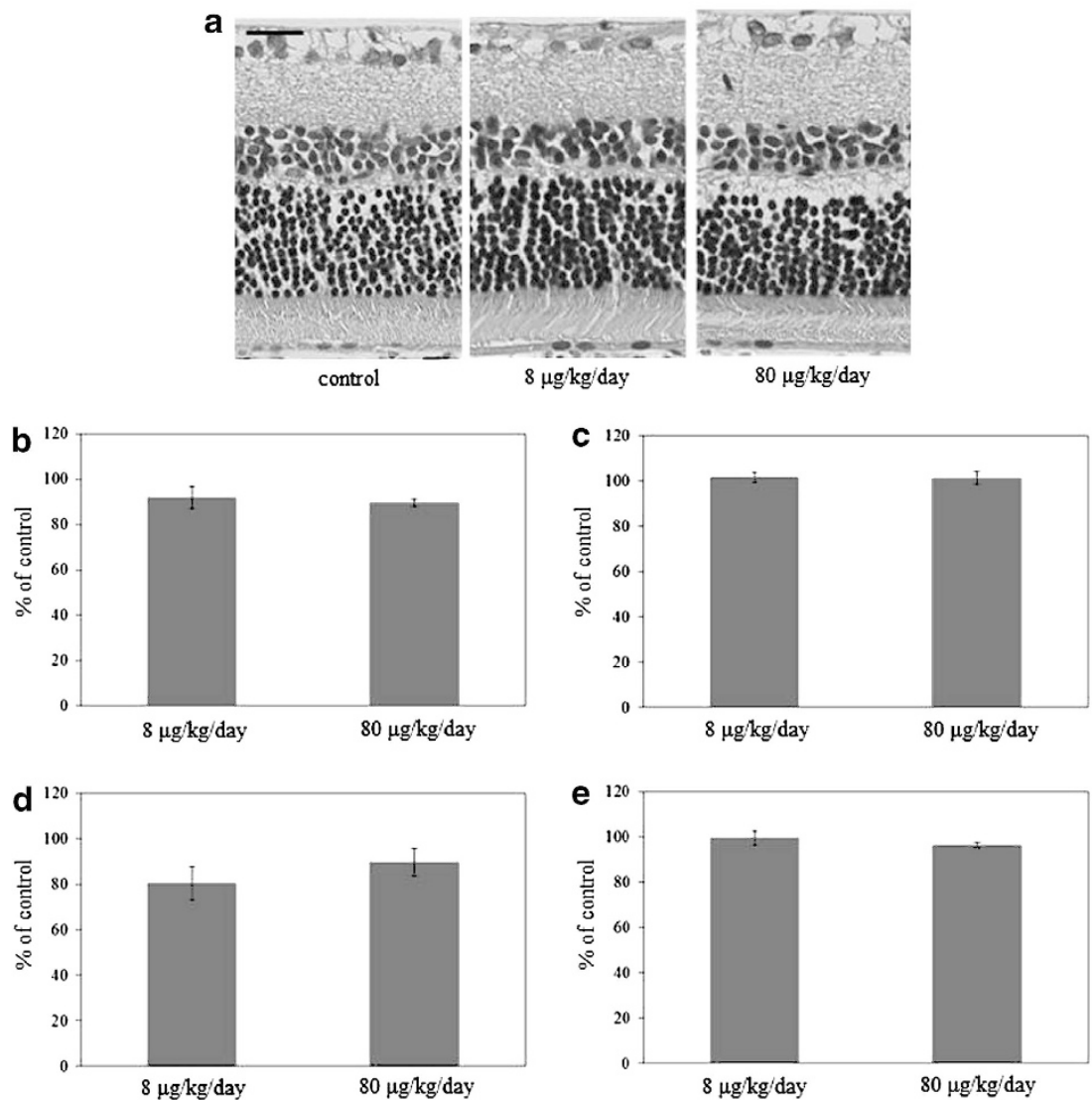

Figure 3 Retinal thickness layer analysis. (a) Light micrographs of the retina of an eye treated with $8 \mu \mathrm{g} / \mathrm{kg} / \mathrm{day}$ or $80 \mu \mathrm{g} / \mathrm{kg} / \mathrm{day}$ aldosterone for 6 weeks, and a normal control eye. Change in mean thickness of the (b) inner plexiform layer (IPL), (c) inner nuclear layer (INL), (d) outer plexiform layer (OPL), and (e) outer nuclear layer (ONL). Results are expressed as the mean \pm S.E.M. ( $n=4$ in each group). Scale bar, $20 \mu \mathrm{m}$ 


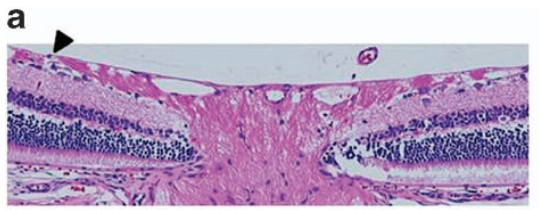

b

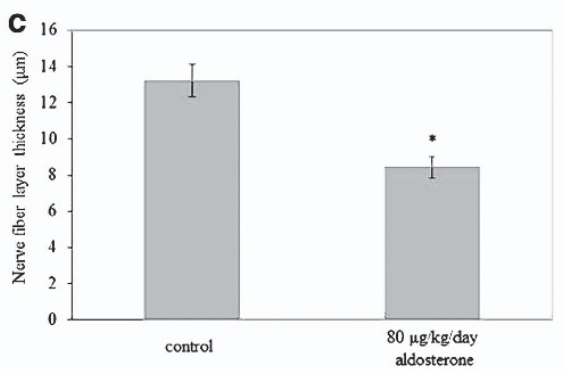

Figure 4 Optic nerve degeneration in aldosterone-treated rats. Representative photos of HE-stained sections in normal (a) and aldosterone-treated (b) rats. Sections illustrate the thinning of the retinal nerve fiber layer (arrowheads) in the aldosterone-treated rats as compared with normal rats. Cupping extends to the posterior aspect of the inner retinal layer (allows). Scale bar, $20 \mu \mathrm{m}$. (c) Quantitative analysis was performed in order to show the significant difference in the thickness of the nerve fiber layer in the aldosterone-treated rats. Results are expressed as the mean \pm S.E.M. ( $n=4$ in each group). ${ }^{*} P<0.01$ versus control (independent Student's $t$-test)

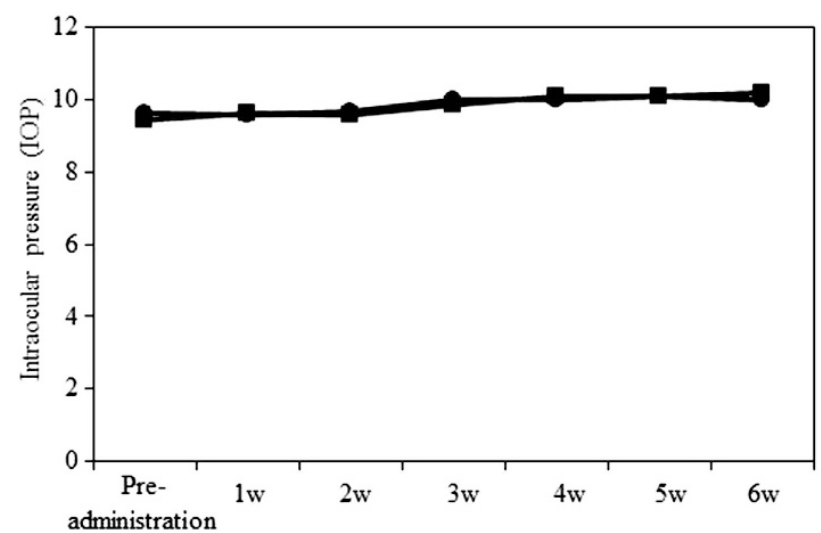

Figure 5 Normal intraocular pressure (IOP) in aldosterone-treated rats. There were no significant differences in the IOP between the vehicle- and $80 \mu \mathrm{g} / \mathrm{kg} / \mathrm{day}$ aldosterone- treated rats. $\mathbf{0}$ : vehicle-treated rats, $\mathbf{\square}$ : aldosterone-treated rats. Results are expressed as the mean \pm S.E.M. $(n=4$ in each week)

possibility that aldosterone may very well have a role in RGC death in human NTG.

MR is expressed in RGCs and in the cells of the inner nuclear layer in the normal retina. ${ }^{22,23}$ Many studies have previously demonstrated that Ang II, the principal effector of the RAAS, induces cellular changes through NADPH oxidasemediated reactive oxygen species (ROS) production. ${ }^{24-26} \mathrm{We}$ have previously reported that the expression of AT1-R increases $12 \mathrm{~h}$ after reperfusion. ${ }^{19,21}$ ROS production after 12-h reperfusion is mediated via a NADPH oxidase pathway. ${ }^{21}$ However, the combined treatment of aldosterone with the AT1-R antagonist, candesartan, provided no protective effect against the retinal ischemia-reperfusion injury. ${ }^{20}$ Thus, it may be the aldosterone that has a critical role in this ischemia-reperfusion model. Moreover, these results suggest that retinal ischemic injury might occur due to ROS production via the local RAAS. It has been reported that aldosterone induces apoptosis of proximal tubular cells, ${ }^{27}$ mesangial cells $^{28}$ and cardiac myocytes ${ }^{29}$ in a ROS-dependent manner. On the basis of these findings, we assume that RGC death in our model may be induced by aldosterone in a ROSdependent manner.

Ischemia/inflammation may have a role in the pathogenesis of NTG because of an increase in the plasma endothelin-1 and the macrophage chemoattractant protein 1 (MCP-1) ${ }^{30}$ Aldosterone is a potent stimulator of inflammation. ${ }^{31,32}$ Wilkinson-Berka et al. ${ }^{22}$ recently reported that retinal MCP-1 mRNA and protein were modulated by aldosterone, which was reduced by spironolactone. On the basis of these findings, they speculated there was a pathogenic role for MR-aldosterone in retinal inflammation.

Although intravitreal injection of aldosterone reduced the number of RGCs, it did not affect other retinal neurons. ${ }^{20} \mathrm{~A}$ previous study has reported finding elevated plasma aldosterone levels when $0.66 \mu \mathrm{g} / \mathrm{h}$ aldosterone was administered subcutaneously by implanted osmotic pumps. ${ }^{18}$ Moreover, systemic administration of $0.75 \mu \mathrm{g} / \mathrm{h}$ aldosterone was found to exacerbate the pathological neovascularization in experimental retinopathy of prematurity. ${ }^{22}$ In our study, systemic administration of $80 \mu \mathrm{g} / \mathrm{kg} / \mathrm{day}$, that is, $0.67-0.83 \mu \mathrm{g} / \mathrm{h}$, aldosterone significantly reduced the number of RGCs. Although we did not investigate the blood-retinal-barrier penetration of aldosterone, we assume that the effective concentration of aldosterone did reach the retina in our study.

Primary aldosteronism in the essential hypertensive population has been reported to range from 5 to $15 \%$, with the overall incidence most likely to be around $10 \% .{ }^{33,34}$ Although hypertension has been associated with glaucoma in some population-based studies, ${ }^{35-37}$ other prospective studies have failed to verify any association between incident glaucoma and the systolic or diastolic blood pressures. ${ }^{38,39}$ This could be attributed to the distribution of age or racial variability, with a higher susceptibility to open-angle glaucoma among hypertensive white as compared with black subjects. Another possible explanation for this discrepancy is that one 

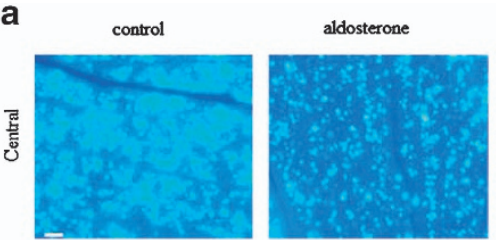

aldosterone +

spironolactone
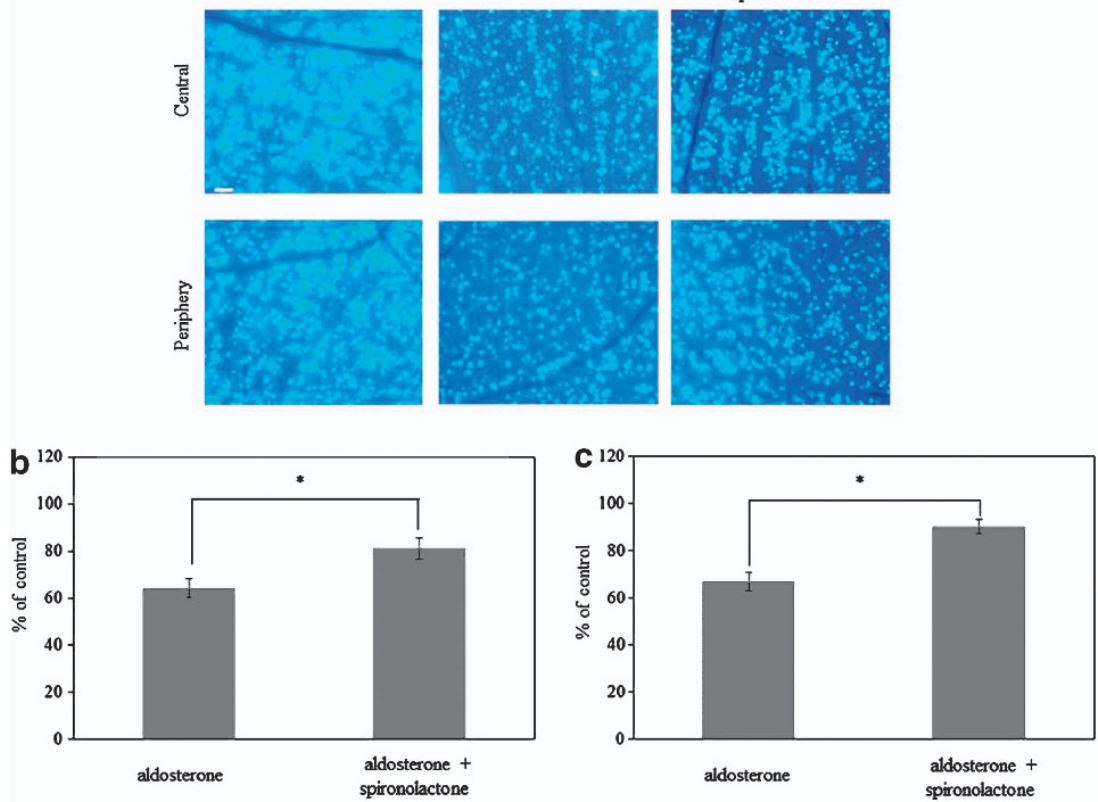

Figure 6 Effect of spironolactone on aldosterone-induced retinal ganglion cell death. (a) Retrograde labeling of RGCs in a normal control eye and aldosterone-treated rats with or without spironolactone for 6 weeks. Scale bar, $100 \mu \mathrm{m}$. RGCs were counted in the central (b) and peripheral (c) areas. Results are expressed as the mean \pm S.E.M. ( $n=4$ in each group). ${ }^{*} P<0.05$ versus aldosterone-treated rats (Tukey's honestly significant difference test)

study could have included fewer patients with hypertension due to primary aldosteronism in relation to the other study.

In conclusion, the RGC loss observed after systemic administration of aldosterone was a time-dependent loss that occurred without any elevation in the IOP. We believe this animal model offers a powerful system for investigating mechanisms of neurodegeneration in NTG and for developing therapies directed at the IOP-independent mechanism of RGC loss. Further clinical studies will need to be undertaken to clarify the specific relationship between NTG and primary aldosteronism.

\section{Materials and Methods}

Animals. Male Sprague-Dawley rats weighing 200 to $250 \mathrm{~g}$ were obtained from Charles River Japan (Yokohama, Japan). Rats were permitted free access to standard rat food (Oriental Yeast Co., Ltd., Tokyo, Japan) and tap water. Animal care and all experiments were conducted in accordance with the approved standard guidelines for animal experimentation of the Kagawa University Faculty of Medicine and adhered to the ARVO Statement for the Use of Animals in Ophthalmic and Vision Research.

Drugs. Aldosterone and spironolactone were obtained from Sigma-Aldrich (St. Louis, MO, USA). Aldosterone was dissolved in dimethyl sulfoxide (DMSO) to produce the stock solutions, which were then diluted to the final required concentrations. The final DMSO concentration never exceeded 5\%. After dissolving $10 \mathrm{mg} / \mathrm{kg} /$ day spironolactone ${ }^{20}$ in carboxymethyl cellulose (CMC) to produce the stock solution, feeding needles were then used to orally administer the solution to each of the animals. The final CMC concentration never exceeded $0.5 \%$. For the control group, additional animals were treated with vehicle only (0.5\% CMC in PBS).

Experimental animals. Aldosterone ( 8 or $80 \mu \mathrm{g} / \mathrm{kg} / \mathrm{day}$ ) or vehicle was administered to the experimental animals using a subcutaneous osmotic minipump (Alzet model 2006, DURECT Corporation, Cupertino, CA, USA). The minipumps were implanted subcutaneously into the mid-scapular region.
Histological examination. For the histological examination, rats were anesthetized by intraperitoneal injection of pentobarbital sodium $(50 \mathrm{mg} / \mathrm{kg})$ at 6 weeks after the systemic administration of aldosterone and then perfused intracardially with phosphate-buffered saline (PBS), followed by perfusion with $4 \%$ paraformaldehyde in PBS. Subsequently, the anterior segments, including the lens, were removed. The posterior eyecups were then embedded in paraffin, and thin sections (5- $\mu \mathrm{m}$ thickness) were cut using a microtome. Each of the sections was carefully cut to include the full length from the superior to inferior along the vertical meridian through the optic nerve head. Each eye was then mounted on a silane-coated glass slide and stained with hematoxylin and eosin (HE). Scleral thickness was measured to confirm that the sections were not oblique sections.

Five sections were randomly selected in each eye. One investigator with no prior knowledge of the treatments administered was responsible for performing all of the light microscopic examinations (magnification; $10 \times 100$; Olympus BX-51, Olympus Inc., Tokyo, Japan). A microscopic image of each section within 0.5 to $1 \mathrm{~mm}$ superior of the optic disc was scanned. In each computer image, the thickness of the IPL, INL, OPL, and ONL were measured.

$\mathrm{HE}$-stained retinal sections with the optic nerve stump were used to examine the morphology of the optic nerve head.

Retrograde labeling of retinal ganglion cells. At 7 days before sacrifice, Fast Blue (Polysciences Inc., Warrington, PA, USA) was injected bilaterally into the superior colliculi of anesthetized rats. The skull was exposed and kept dry and clean. After identifying and marking the bregma, a small window was drilled in the scalp in both the right and left hemispheres. The windows were drilled to a depth of $3.6 \mathrm{~mm}$ from the surface of the skull and located at $6.8 \mathrm{~mm}$ behind the bregma on the anteroposterior axis, and $1.5 \mathrm{~mm}$ lateral to the midline. Using a Hamilton syringe (Hamilton Co., Reno, NV, USA), $1.5 \mu$ of $3 \%$ Fast Blue was slowly injected into the bilateral superior colliculi. After suturing the skin over the wound, antibiotic ointment was applied.

Tissue preparation and assessment of RGC survival. Animals were sacrificed using an overdose of pentobarbital at 1 week after fluorescent dye application. Whole, flat-mounted retinas were then assayed for RGC density. Rat eyes were enucleated and fixed in $4 \%$ paraformaldehyde for $10 \mathrm{~h}$ at room temperature. After removal of the anterior segments, the resultant posterior eyecups were left in place. Subsequently, four radial cuts were made in the 
periphery of each eyecup, with the retina then carefully separated from the retinal pigment epithelium. To prepare the flat mounts, the retina was dissociated from the underlying structures, flattened by making four radial cuts, and then spread on a gelatin-coated glass slide. Labeled RGCs were visualized under a fluorescence microscope (Olympus BX-51/DP-72, Olympus, Tokyo, Japan) with an ultraviolet filter (excitation filter, $330-385 \mathrm{~nm}$; barrier filter, $420 \mathrm{~nm}$ ). Fluorescence-labeled RGCs were counted in 12 microscopic fields of retinal tissue from two regions in each quadrant at two different eccentricities, $1 \mathrm{~mm}$ (central) and $4 \mathrm{~mm}$ (peripheral) away from the optic disc. Image-Pro Plus software (Version 4.0, Media Cybernetics, Bethesda, MD, USA) was used to count the total number of RGCs in each eye.

IOP measurement. Rats were anesthetized using an intraperitoneal injection of $50 \mathrm{mg} / \mathrm{kg}$ pentobarbital sodium prepared at room temperature. Subsequently, topical $0.4 \%$ oxybuprocaine (Benoxyl; Santen Pharmaceuticals, Osaka, Japan) was then applied to both eyes.

An osmotic minipump was subcutaneously implanted at the dorsum of the neck and used to infuse the aldosterone. The IOP was measured before and every week after the implantation. All of the IOP measurements were made by a TonoLab tonometer (TioLat, Inc., Helsinki, Finland), which recorded the mean of six readings using the optimal variability grade.

Statistical analysis. All data are presented as the mean \pm S.E.M.. Data were analyzed using an independent Student's $t$-test, Dunnett's multiple comparison test, or Tukey's honestly significant difference test, as appropriate. Statistical analyses were performed using SPSS version 19.0 (SPSS Inc., Chicago, IL, USA). A $P$-value of $<0.05$ was considered statistically significant.

\section{Conflict of Interest}

The authors declare no conflict of interest.

1. Cartwright MJ, Anderson DR. Correlation of asymmetric damage with asymmetric intraocular pressure in normal-tension glaucoma (low-tension glaucoma). Arch Ophthalmol 1988; 106: 898-900.

2. Crichton A, Drance SM, Douglas GR, Schulzer M. Unequal intraocular pressure and its relation to asymmetric visual field defects in low-tension glaucoma. Ophthalmology 1989; 96: $1312-1314$.

3. Abedin S, Simmons RJ, Grant WM. Progressive low-tension glaucoma: treatment to stop glaucomatous cupping and field loss when these progress despite normal intraocular pressure. Ophthalmology 1982; 89: 1-6.

4. de Jong N, Greve EL, Hoyng PF, Geijssen HC. Results of a filtering procedure in low tension glaucoma. Int Ophthalmol 1989; 13: 131-138.

5. Tezel G, Siegmund KD, Trinkaus K, Wax MB, Kass MA, Kolker AE. Clinical factors associated with progression of glaucomatous optic disc damage in treated patients. Arch Ophthalmol 2001; 119: 813-818.

6. Flammer J, Haefliger 10, Orgül S, Resink T. Vascular dysregulation: a principal risk factor for glaucomatous damage? J Glaucoma 1999; 8: 212-219.

7. Hayreh SS. The role of age and cardiovascular diseases in glaucomatous optic neuropathy. Surv Ophthalmol 1999; 43: S27-S42.

8. Bonomi L, Marchini G, Marraffa M, Bernardi P, Morbio R, Varotto A. Vascular risk factors for primary open angle glaucoma: the Enga-Neumarkt Study. Ophthalmology 2000; 107: 1287-1293.

9. Drance S, Anderson DR, Schulzer M. Collaborative Normal-Tension Glaucoma Study Group. Risk factors for progression of visual field abnormalities in normal-tension glaucoma. Am J Ophthalmol 2001; 131: 699-708.

10. Gottfredsdottir MS, Allingham RR, Shields MB. Physicians' guide to interactions between glaucoma and systemic medications. J Glaucoma 1997; 6: 377-383.

11. Brunner HR, Laragh JH, Baer L, Newton MA, Goodwin FT, Krakoff LR et al. Essential hypertension: renin and aldosterone, heart attack and stroke. N Engl J Med 1972; 286: 441-449.

12. Alderman MH, Madhavan S, Ooi WL, Cohen H, Sealey JE, Laragh JH. Association of the renin-sodium profile with the risk of myocardial infarction in patients with hypertension. N Engl J Med 1991; 324: 1098-1104.

13. Rossi GP, Sachetto A, Visentin P, Canali C, Graniero GR, Palatini P et al. Changes in left ventricular anatomy and function in hypertension and primary aldosteronism. Hypertension 1996; 27: 1039-1045

14. Halimi J-M, Mimran A. Albuminuria in untreated patients with primary aldosteronism or essential hypertension. J Hypertens 1995; 13: 1801-1802.

15. Takeda R, Matsubara T, Miyamori I, Hatakeyama H, Morise T. Vascular complications in patients with aldosterone producing adenoma in Japan: comparative study with essentia hypertension. The Research Committee of Disorders of Adrenal Hormons in Japan. J Endocrinol Invest 1995; 18: 370-373.
16. Nishimura M, Uzu T, Fujii T, Kuroda S, Nakamura S, Inenaga T et al. Cardiovascular complications in patients with primary aldosteronism. Am J Kidney Dis 1999; 33: 261-266.

17. Rocha R, Chander PN, Zuckerman A, Stier Jr CT. Role of aldosterone in renal vascular injury in stroke-prone hypertensive rats. Hypertension 1999; 33: 232-237.

18. MacLeod AB, Vasdev S, Smeda JS. The role of blood pressure and aldosterone in the production of hemorrhagic stroke in captopril-treated hypertensive rats. Stroke 1997; 28: 1821-1829.

19. Fukuda K, Hirooka K, Mizote M, Nakamura M, Itano T, Shiraga F. Neuroprotection against retinal ischemia-reperfusion injury by blocking the angiotensin II type 1 receptor. Invest Ophthalmol Vis Sci 2010; 51: 3629-3638.

20. Liu Y, Hirooka K, Nishiyama A, Lei B, Nakamura M, Itano T et al. Activation of the aldosterone/mineralocorticoid receptor system and protective effects of mineralocorticoid receptor antagonism in retinal ischemia-reperfusion injury. Exp Eye Res 2012; 96: 116-123.

21. Fujita $T$, Hirooka $K$, Nakamura $T$, Itano $T$, Nishiyama A, Nagai $Y$ et al. Neuroprotective effects of angiotensin II type 1 receptor (AT1-R) blocker via modulating AT1-R signaling and decreased extracellular glutamate levels. Invest Ophthalmol Vis Sci 2012; 53 4099-4110.

22. Wilkinson-Berka JL, Tan G, Jaworski K, Miller AG. Identification of a retinal aldosterone system and the protective effects of mineralocorticoid receptor antagonism on retinal vascular pathology. Circ Res 2009; 104: 124-133.

23. Zhao M, Valamanesh F, Celerier I, Savoldelli M, Jonet L, Jeanny JC et al. The neuroretina is a novel mineralocorticoid target: aldosterone up-regulates ion and water channels in Müller glial cells. FASEB J 2010; 24: 3405-3415.

24. Griendling KK, Sorescu D, Ushino-Fukai M. NAD(P)H oxidase: role in cardiovascular biology and disease. Cir Res 2000; 86: 494-501.

25. Abe J, Berk BC. Reactive oxygen species as mediators of signal transduction in cardiovascular diseases. Trends Cardiovasc Med 1998; 8: 59-64.

26. Yoshizumi M, Tsuchiya K, Tamaki T. Signal transduction of reactive oxygen species and mitogen-activated protein kinases in cardiovascular disease. J Med Invest 2001; 48: $11-24$.

27. Patni H, Mathew JT, Luan L, Franki N, Chander PN, Singhal PC. Aldosterone promotes proximal tubular cell apoptosis: role of oxidative stress. Am J Physiol Renal Physiol 2007 293: F1065-F1071.

28. Mathew JT, Patni H, Chaudhary AN, Liang W, Gupta A, Chander PN et al. Aldosterone induces mesangial cell apoptosis both in vivo and in vitro. Am J Physiol Renal Physiol 2008 295: F73-F81.

29. Hayashi H, Kobara M, Abe M, Tanaka N, Gouda E, Toba H et al. Aldosterone nongenomically produces NADPH oxidase-dependent reactive oxygen species and induces myocyte apoptosis. Hypertension Res 2008; 31: 363-375.

30. Lee NY, Park HY, Park CY, Ahn MD. Analysis systemic endothelin-1, matrix metalloproteinase-9, macrophage chemoattractant protein 1 , and high-sensitivity C-reactive protein in normal-tension glaucoma. Curr Eye Res 2012; 37: 1121-1126.

31. Rocha R, Martin-Berger CL, Yang P, Scherrer R, Delyani J, McMahon E. Selective sldosterone blockade prevents angiotensin II/salt-induced vascular inflammation in the rat heart. Endocrinology 2002; 143: 4828-4836.

32. Blasi ER, Rocha R, Rudolph AE, Blomme EA, Polly ML, McMahon EG. Aldosterone/salt induces renal inflammation and fibrosis in hypertensive rats. Kidney Int 2003; 63 1791-1800.

33. Gordon RD, Stowasser M, Tunny TJ, Klemm SA, Rutherford JC. High incidence of primary aldosteronism in 199 patients referred with hypertension. Clin Exp Pharmacol Physiol 1994; 21: 315-318.

34. Komiya I, Yamada T, Takasu N, Asawa T, Akamine H, Yagi N et al. An abnormal sodium metabolism in Japanese patients with essential hypertension, judged by serum sodium distribution, renal function and the renin-aldosterone system. J Hypertens 1997; 15: 65-72.

35. Dielemans I, Vingerling JR, Algra D, Hofman A, Grobbee DE, de Jong PT. Primary openangle glaucoma, intraocular pressure, and systemic blood pressure in the general elderly population. The Rotterdam Study. Ophthalmology 1995; 102: 54-60.

36. Bonomi L, Marchini G, Marraffa M, Bernardi P, Morbio R, Varotto A. Vascular risk factors for primary open angle glaucoma; the Egna-Neumarkt Study. Ophthalmology 2000; 107 : 1287-1293.

37. Mitchell P, Lee AJ, Rochtchina E, Wang JJ. Open-angle glaucoma and systemic hypertension: the blue mountain eye study. J Glaucoma 2004; 13: 319-326.

38. Laske MC, Connell AM, Wu SY, Hyman LG, Schachat AP. Risk factors for open-angle glaucoma. The Barbados Eye Study. Arch Ophthalmol 1995; 113: 918-924.

39. Leske MC, Wu SY, Nemesure B, Hennis A. Incident open-angle glaucoma and blood pressure. Arch Ophthalmol 2002; 120: 954-959.

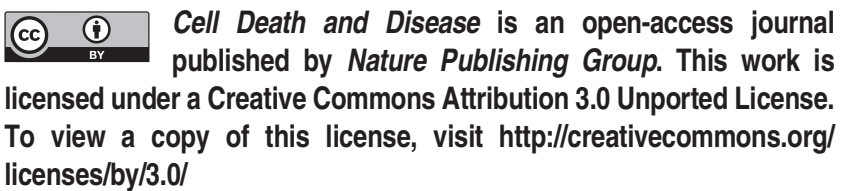

Cell Death and Disease is an open-access journal published by Nature Publishing Group. This work is To view a copy of this license, visit http://creativecommons.org/ licenses/by/3.0 